\title{
Development of a new engobe for raku ceramics
}

\author{
Young Joo Kwon, Dong Ha Hwang and Byung Ha Lee ${ }^{\dagger}$ \\ Department of Material Science \& Engineering, Myongji University, Yongin 449-728, Korea
}

(Received November 12, 2013)

(Revised November 28, 2013)

(Accepted December 6, 2013)

\begin{abstract}
Red clay has been used for making rakuyaki for the past 400 years. Because the resources for red clay in Japan are being depleted, many potters in Japan began to develop new materials which can replace red clay. In this study, It is analyzed that the chemical and physical properties of red clay from Shigaraki (Shiga, Japan), and developed a novel engobe which can be used for making Rakuyaki instead of Shigaraki red clay. Results from Raman spectroscopic examination showed that ferric oxide content in Shigaraki red clay is $9.4 \%$ (Goethite 5\%, Wustite $4.4 \%$ ), and that the mechanism of red color development by the firing at $900^{\circ} \mathrm{C}$ for $10 \mathrm{~min}$ is the chemical transformation of Goethite into Hematite, and the subsequent formation of solid solution with Alumina and Silica. To make similar ferric oxide content to that of Shigaraki red clay, we added $5 \mathrm{~g}$ of Goethite and $9 \mathrm{~g}$ of Wustite to $100 \mathrm{~g}$ of White kaolin from Hadong area (Gyeongsangnam-do, Korea). The $\mathrm{L}^{*} \mathrm{a} * \mathrm{~b} *$ color scale of the mixture was 56.83, 27.22, and 23.28, respectively, and stable red color was successfully developed under the same firing condition used for Shigaraki red clay.
\end{abstract}

Key words Rakuyaki, Red clay, Shigaraki red clay, Wustite, Hematite

\section{적색 RAKU 도자기의 화장토 개발에 관한 연구}

권영주, 황동하, 이병하

명지대학교 신소재공학과, 용인, 449-728

(2013년 11월 12일 접수)

(2013년 11월 28일 심사완료)

(2013년 12월 6일 게재확정)

요 약 일본에서 적색 라꾸용 원료로 사용중인 황토는 장기간 사용으로 매장량이 감소되어 대체 원료를 개발하고자 노 력중에 있다. 본 연구에서는 현재 일본 라꾸요장에서 사용되는 일본 시가현 고우가시 시가라끼 황토를 분석하여 이와 동일 한 색상의 화장토를 개발 하고자 하였다. 일본 시가라끼 황토에 함유된 Goethite와 Wustite의 양을 Raman에 의한 “상대 정 량분석법”으로 분석한 결과 일본 시가라끼 황토 내에 함유된 산화철 $9.4 \%$ 에는 Goethite가 $5 \%$, Wustite가 $4.4 \%$ 로 구성되 어 있으며 이를 $900^{\circ} \mathrm{C}$ 에 넣어 10 분간 소성 시 적색을 나타내는 것은 Goethite가 Hematite로 전이되면서 Hematite에 Alumina와 Silica가 고용되기 때문이다. 일본 시가라끼 황토에 함유된 산화철의 양을 기초로 일본 적색 화장토와 같은 색상 을 나타내는 것은 하동 White Kaolin $100 \mathrm{~g}$ 에 Goethite를 $5 \mathrm{~g}$, Wustite를 $9 \mathrm{~g}$ 을 첨가한 것이었으며 UV측정결과 $\mathrm{L}^{*} \mathrm{a} * \mathrm{~b}^{*}$ 값은 각각 $56.83,27.22,23.28$ 이었다.

1. 서

400년전 일본에서 탄생한 라꾸야끼는 중국 당나라의 당 삼채의 영향을 받은 도자기로 라꾸야끼의 창시자인 조지로에 의해서 만들어졌다[1]. 기와공이던 조지로는 센 노리큐와의 만남으로 일반 도자기와는 완전 다른 방식의

\footnotetext{
Corresponding author

Tel: +82-31-330-6461

Fax: +82-31-330-6469

E-mail: lbh@mju.ac.kr
}

차도구용 라꾸다완이 만들어졌다.

특징으로는 물레를 사용하지 않고 손으로만 빚어 만들 었으며, 초벌한 도자기를 $900^{\circ} \mathrm{C}$ 이상의 고온에서 소성하 는 방식으로 적색 다완은 $900^{\circ} \mathrm{C}$ 에 넣어 10 분간, 검은색 다완은 $1180^{\circ} \mathrm{C}$ 에서 넣어 약 10 분간 급열 - 급냉하는 방 식으로 만들어졌다[2-4]. 초기 적색 다완에 사용된 황토 는 일본 교토 주변에서 산출되는 황토를 이용하여 붉은 색상을 나타냈으나, 최근 원료의 고갈 및 채취장소의 택 지화로 인하여 채취가 어렵게 되었다.

이로 인하여 각 연구 단체 및 전문 라꾸 요장에서는 
적색 라꾸에 사용할 황토를 개발하고자 하는 노력이 본 격화 되고 있다[5]. 일반 황토의 경우 $900^{\circ} \mathrm{C}$ 로 급열하여 급냉하는 경우 황갈색의 색상을 나타내는데, 일본 라꾸 도자기에 사용되는 황토는 $900^{\circ} \mathrm{C}$ 에서 급열 - 급냉하였을 경우 적색을 나타낸다[6].

본 연구에서는 앞서 선행된 연구[6]를 바탕으로 국내 에서 산출되는 원료를 사용하여 일본 고유의 적색 라꾸 다완에서 발색된 적색 화장토를 개발하고자 하였다.

\section{2. 실험방법}

\section{1. 사용 원료의 성분 분석}

적색 라꾸에 사용된 시가라끼 황토와 라꾸 개발에 사 용된 국내산 적색 화장토 원료의 성분을 알아보기 위하 여 XRF 분석을 하였다.

\section{2. 화장토 시유 및 소성}

Table 1과 같이 조합한 화장토를 건조한 라꾸 시험편 에 시유한 다음 $800^{\circ} \mathrm{C}$ 에서 30 분간 초벌 소성하였다. 초 벌 소성한 시험편을 $900^{\circ} \mathrm{C}$ 로 유지된 전기로에 넣어 10 분간 재벌소성 하였다.

\section{3. 결정상 분석}

\subsubsection{Raman spectroscopy 분석}

시가라끼 황토와 개발된 적색화장토의 결정상 특성(일 본 시가라끼 황토와 영주 황토내에 함유되어 있는 Goethite $(\mathrm{FeO}(\mathrm{OH}))$ 와 Wustite $(\mathrm{FeO})$ 의 양 $)$ 을 알아보기 위하여 Raman spectroscopy(Lambda solutions, Inc.,

Table 1

\begin{tabular}{lllll}
\multicolumn{4}{l}{ Mix of engobe (wt.\%) } \\
\hline No. & White Kaolin & $\mathrm{FeO}(\mathrm{OH})$ & $\mathrm{FeO}$ & Note \\
\hline 1 & 100 & $1-25$ & & \\
2 & 100 & & $1-19$ & Odd number \\
3 & 100 & 21 & $1,3,5$ & \\
4 & 100 & 5,7 & $1-9$ & \\
\hline
\end{tabular}

U.S.A)RP 532-US를 사용하여 분석하였다.

\subsubsection{XRD 분석}

적색화장토를 개발하기 위하여 White Kaolin에 첨가 하는 $\mathrm{FeO}(\mathrm{OH})$ 와 $\mathrm{FeO}$ 를 $900^{\circ} \mathrm{C}$ 에서 10 분간 소성하였을 경우 결정상을 알아보기 위하여 XRD 분석하였다.

\section{4. 화장토의 조합}

시가라끼 황토를 국내 화장토로 대체하기 위하여 시가 라끼 황토의 성분 분석 자료[6]를 근거로 Table 1과 같 이 하동 White Kalion $100 \%$ 에 각각 $\mathrm{FeO}(\mathrm{OH})$ 를 1 $25 \%$ 까지 $2 \%$ 씩 증가하여 첨가 하였고, $\mathrm{FeO}$ 는 1 19\% 까지 $2 \%$ 씩 증가하여 조합하였다.

\section{5. 색상 분석}

적색라꾸에 사용되는 시가라끼 황토와 개발된 적색 화장 토의 색상을 알아보기 위하여 UV-vis Spectrophotometer (2401-PC, Shimadzu, Japan)을 사용하여 측정하였으며, 멘셀(Muncell)색 표시인 색상(H: hue), 명도(V: value), 채도 $(\mathrm{C}$ : chroma)와 CIE-L*a*b*값으로 나타내었다.

\section{3. 결과 및 고찰}

\section{1. 시가라끼 황토와 영주 황토의 특성 비교}

\subsection{1. 사용 원료의 성분 분석결과}

Table 2에서와 같이 일본 황토내에 산화철의 함유량은 $9.43 \%$ 로 높고 이들은 대부분 Goethite 형태로 존재하며 일부 Wustite가 존재하였다[6]. 그러나 국내 대부분의 황 토의 경우 산화철 함유량이 $8 \%$ 이하였으며 Hematite 형태로 존재하고 있다.

\subsubsection{Raman spectroscopy 분석 결과}

국내 황토 중 영주 황토만이 Fig. 1에서와 같이 일본 시가라끼 황토와 같은 Goethite와 Wustite로 존재하는 것을 알 수 있으며, 일본 시가라끼 황토와 영주 황토내 에 함유되어 있는 Goethite와 Wustite의 양을 Raman에

Table 2

Component analysis of used materials (wt.\%)

\begin{tabular}{llllllllll}
\hline Sample & $\mathrm{SiO}_{2}$ & $\mathrm{Al}_{2} \mathrm{O}_{3}$ & $\mathrm{Fe}_{2} \mathrm{O}_{3}$ & $\mathrm{TiO}_{2}$ & $\mathrm{MgO}$ & $\mathrm{CaO}$ & $\mathrm{Na}_{2} \mathrm{O}$ & $\mathrm{K}_{2} \mathrm{O}$ & $\mathrm{Ig} . \operatorname{loss}$ \\
\hline Red clay (Shigaraki) & 60.63 & 26.04 & $\mathbf{9 . 4 3}$ & 1.01 & 0.55 & 0.47 & 0.14 & 1.51 & 0.22 \\
Red clay (Yeongju) & 53.96 & 30.76 & 8.10 & 0.98 & 2.44 & 0.47 & 0.24 & 2.73 & 0.32 \\
Kaolin (Hadong/White) & 48.40 & 34.32 & 0.53 & - & 0.20 & 4.59 & 1.02 & 0.55 & 10.39 \\
\hline
\end{tabular}




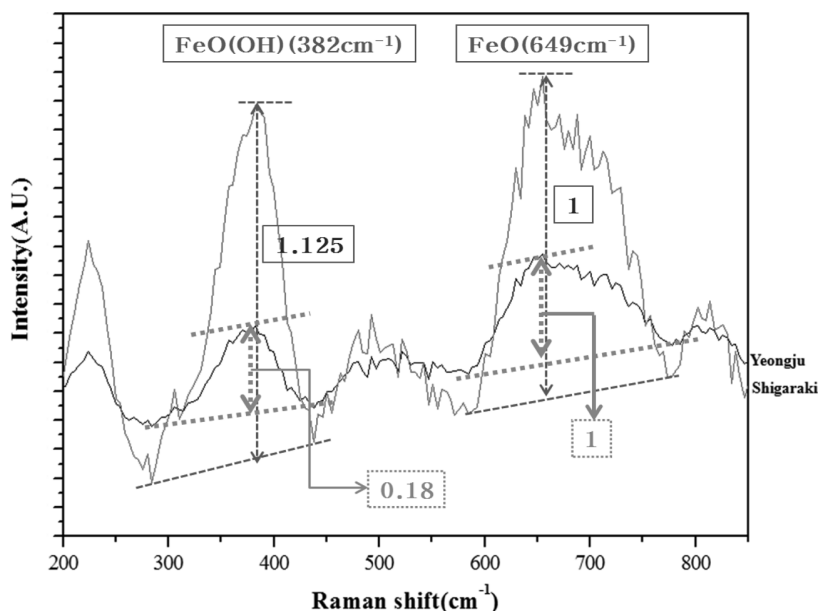

Fig. 1. Raman spectroscopic analysis of red clay from shigaraki and yeongju.

의한 “상대 정량분석법”[7-9]으로 분석하였다. 시가라끼 황토는 $382 \mathrm{~cm}^{-1}$ 에서 Goethite의 특성 peak intensity와 Wustite $649 \mathrm{~cm}^{-1}$ 의 peak intensity의 비를 계산한 결과 $\mathrm{FeO}(\mathrm{OH}): \mathrm{FeO}=1.125: 1$ 이었다.

따라서, 일본 시가라끼 황토 내에 함유되어 있는 산화 철 $9.4 \%$ 에는 Goethite가 $5 \%$, Wustite가 $4.4 \%$ 로 구성 되어 있음을 알 수 있다.

영주 황토의 경우 같은 방법으로 Goethite와 Wustite의 비를 계산하면 $\mathrm{FeO}(\mathrm{OH}): \mathrm{FeO}=0.1815: 1$ 로서 영주 황 토 내에 함유되어 있는 산화철의 $8.1 \%$ 에는 Goethite는 $3.6 \%$ 와 Wustite $4.5 \%$ 로 구성되어 있음을 알 수 있다.

따라서 시가라끼 황토와 영주 황토 내에 함유되어 있 는 산화철은 동일 한 Goethite와 Wustite로 구성되어 있 으나 그들의 함량 차이에 의하여 소성 색상이 달라진다.

\subsubsection{XRD 분석}

황토를 $900^{\circ} \mathrm{C}$ 에서 소성하였을 경우 적색을 발현하는 이유는 황토 내에 Goethite가 Hematite로 전이되면서

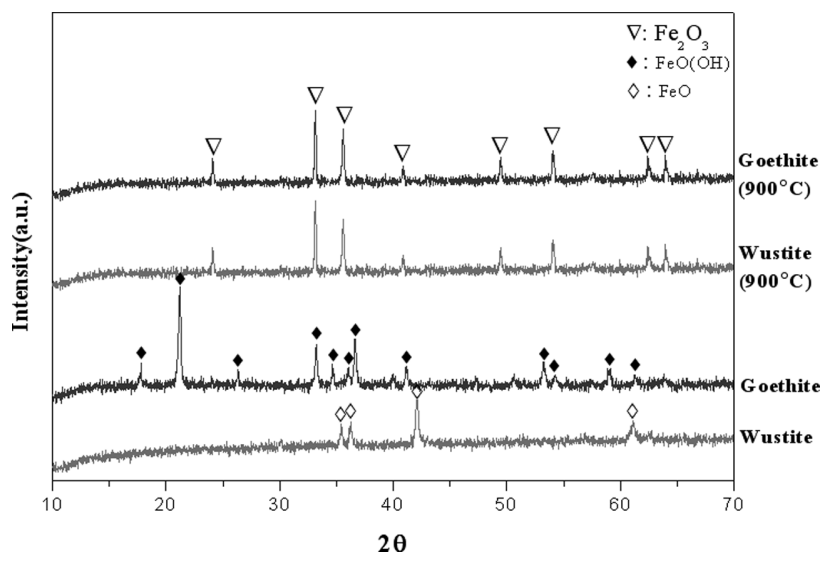

Fig. 2. XRD analysis of Goethite and Wustite which were fired for $10 \mathrm{~min}$ at $900^{\circ} \mathrm{C}$.
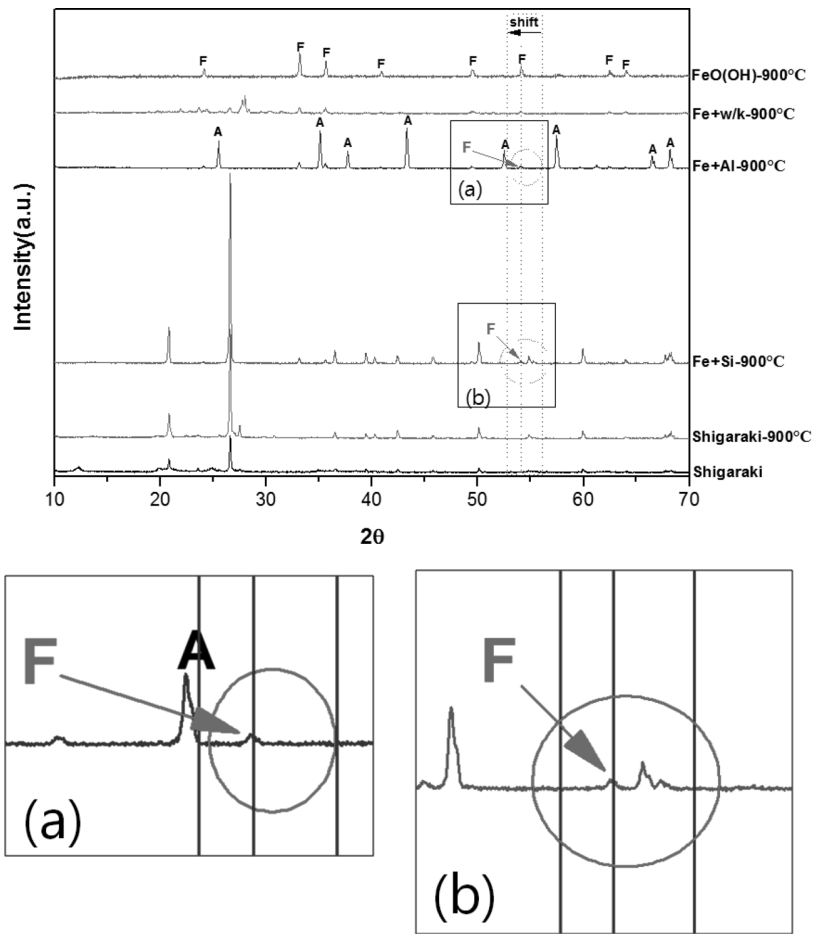

Fig. 3. XRD analysis of Goethite and Wustite which were fired for $10 \mathrm{~min}$ at $900^{\circ} \mathrm{C}$.

Alumina와 Silica를 고용하기 때문이고 Wustite의 경우 는 Hematite로 전이되면서 명도 값은 낮아지고 색상은 핑크 빛을 나타내는 회색임을 알 수 있다. 이를 Fig. 2 와 Fig. 3에서 나타내었다.

\section{2. 화장토의 개발}

즉, 시가라끼 황토를 $900^{\circ} \mathrm{C}$ 에 넣어 10 분간 소성하면 $\mathrm{L}^{*} \mathrm{a} * \mathrm{~b} *$ 값이 52.50, 27.01, 24.08인 Grayish reddish orange color로 발색하였고, 영주 황토의 경우 $\mathrm{L}^{*} \mathrm{a} * \mathrm{~b} *$ 값이 $62.50,18.46,30.33$ 인 Moderate Orange color로 발색하여 영주 황토로 대체하기는 어려웠다.

시가라끼 황토를 대체할 국내 황토가 없어 시가라끼 황토의 분석 자료[6]를 근거로 산화철 함량이 적고 가소 성을 가진 하동 White Kalion을 사용하였으며, 시가라끼 황토 내에 존재하는 산화철이 Goethite와 Wustite로 존 재하므로 White Kaolin에 Goethite와 Wustite를 넣어 개발하고자 하였다.

\subsubsection{White Kaolin(W/K)에 Wustite 첨가한 UV 분석} 결과

White Kaolin에 Wustite를 첨가하였고, Alumina와 Silica에 각각 Wustite를 $7 \%$ 첨가하여 UV를 분석한 결 과 Goethite는 Hematite로 전이 되면서 Hematite에 Alumina와 Silica를 고용하여 적색을 내지만 Wustite의 
Table 3

UV spectroscopic analysis after firing at $900^{\circ} \mathrm{C}$

\begin{tabular}{lllllll}
\hline Sample & $\mathrm{L}^{*}$ & $\mathrm{a}^{*}$ & $\mathrm{~b}^{*}$ & $(\mathrm{H})$ & $(\mathrm{V}) /(\mathrm{C})$ & Color name \\
\hline $\mathrm{Al}_{2} \mathrm{O}_{3}$ (Wustite 7 \%) & 80.40 & 2.25 & 1.78 & $7.6 \mathrm{R}$ & $8.0 / 1.0$ & Pinkish White \\
$\mathrm{SiO}_{2}$ (Wustite 7\%) & 83.71 & 1.47 & 2.11 & $1.6 \mathrm{YR}$ & $8.3 / 0.7$ & Pinkish Gray \\
\hline
\end{tabular}

※ Grayish reddish orange color in which $\mathrm{L}^{*} \mathrm{a} * \mathrm{~b} *$ color space values are $52.50,27.01$, and 24.08 , respectively.

Table 4

UV spectroscopic analysis after firing at $900^{\circ} \mathrm{C}$

\begin{tabular}{llllllll}
\hline No. & Sample & $\mathrm{L}^{*}$ & $\mathrm{a}^{*}$ & $\mathrm{~b}^{*}$ & $(\mathrm{H})$ & $(\mathrm{V}) /(\mathrm{C})$ & Color name \\
\hline 1 & Kaolin & 90.96 & 2.39 & 7.08 & $5.8 \mathrm{R}$ & $9.1 / 1.4$ & Pale Yellowish Pink \\
2 & W/K + Wustite $(100: 1)$ & 87.02 & 2.18 & 5.49 & $5.3 \mathrm{YR}$ & $8.7 / 1.1$ & Pinkish White \\
3 & W/K + Wustite $(100: 3)$ & 82.93 & 2.62 & 4.21 & $2.7 \mathrm{YR}$ & $8.3 / 1.2$ & Pinkish Gray \\
4 & W/K + Wustite $(100: 5)$ & 76.97 & 2.91 & 3.23 & $0.7 \mathrm{YR}$ & $7.6 / 1.1$ & Pinkish Gray \\
5 & W/K + Wustite $(100: 7)$ & 78.01 & 3.33 & 3.45 & $0.3 \mathrm{YR}$ & $7.7 / 1.3$ & Pinkish Gray \\
6 & W/K + Wustite $(100: 9)$ & 73.49 & 3.52 & 2.04 & $5.7 \mathrm{R}$ & $7.3 / 1.2$ & Pinkish Gray \\
7 & W/K + Wustite $(100: 11)$ & 71.21 & 3.92 & 1.32 & $1.3 \mathrm{R}$ & $7.0 / 1.2$ & Pinkish Gray \\
8 & W/K + Wustite $(100: 13)$ & 73.71 & 3.28 & 1.97 & $6.0 \mathrm{R}$ & $7.3 / 1.1$ & Pinkish Gray \\
9 & W/K + Wustite $(100: 15)$ & 73.36 & 2.95 & 1.97 & $6.8 \mathrm{R}$ & $7.3 / 1.0$ & Pinkish Gray \\
10 & W/K + Wustite $(100: 17)$ & 72.13 & 2.97 & 1.40 & $4.1 \mathrm{R}$ & $7.1 / 1.0$ & Pinkish Gray \\
11 & W/K + Wustite $(100: 19)$ & 69.87 & 3.33 & 1.10 & $1.2 \mathrm{R}$ & $6.9 / 1.0$ & Pinkish Gray \\
\hline
\end{tabular}

※ Grayish reddish orange color in which $\mathrm{L}^{*} \mathrm{a} \mathrm{b}^{*}$ color space values are $52.50,27.01$, and 24.08 , respectively.

Table 5

UV spectroscopic analysis of Goethite-added White Kaolin

\begin{tabular}{|c|c|c|c|c|c|c|c|c|}
\hline No. & Sample & $\mathrm{L}^{*}$ & $a^{*}$ & $b^{*}$ & $(\mathrm{H})$ & $(\mathrm{V}) /(\mathrm{C})$ & $\mathrm{EH}$ & Color name \\
\hline 1 & W/K + Goethite $(100: 1)$ & 88.10 & 7.89 & 6.41 & $7.8 \mathrm{R}$ & $8.8 / 2.5$ & 26.035 & Pale Yellowish Pink \\
\hline 2 & $\mathrm{~W} / \mathrm{K}+$ Goethite $(100: 3)$ & 77.58 & 15.91 & 11.64 & $7.3 \mathrm{R}$ & $7.7 / 4.3$ & 16.672 & Moderate Yellowish Pink \\
\hline 3 & W/K + Goethite $(100: 5)$ & 72.65 & 18.92 & 12.58 & $6.6 \mathrm{R}$ & $7.2 / 5.1$ & 14.061 & Moderate Yellowish Pink \\
\hline 4 & W/K + Goethite $(100: 7)$ & 71.26 & 19.05 & 12.16 & $6.3 \mathrm{R}$ & $7.0 / 5.1$ & 14.333 & Moderate Yellowish Pink \\
\hline 5 & W/K + Goethite (100: 9) & 69.53 & 19.86 & 12.53 & $6.2 \mathrm{R}$ & $6.9 / 5.3$ & 13.584 & Moderate Yellowish Pink \\
\hline 6 & $\mathrm{~W} / \mathrm{K}+$ Goethite $(100: 11)$ & 66.85 & 21.04 & 14.60 & 7.1R & $6.6 / 5.6$ & 11.203 & Moderate Yellowish Pink \\
\hline 7 & $\mathrm{~W} / \mathrm{K}+$ Goethite $(100: 13)$ & 63.17 & 23.98 & 16.72 & $7.2 \mathrm{R}$ & $6.2 / 6.3$ & 7.959 & Dark Yellowish Pink \\
\hline 8 & $\mathrm{~W} / \mathrm{K}+$ Goethite $(100: 15)$ & 58.74 & 26.99 & 19.20 & $7.4 \mathrm{R}$ & $5.8 / 7.0$ & 4.880 & Dark Yellowish Pink \\
\hline 9 & W/K + Goethite $(100: 17)$ & 57.14 & 28.42 & 20.19 & $7.4 \mathrm{R}$ & $5.6 / 7.3$ & 4.138 & Moderate Redish Orange \\
\hline 10 & W/K + Goethite (100 : 19) & 55.27 & 29.13 & 20.58 & $7.4 \mathrm{R}$ & $5.4 / 7.4$ & 4.092 & Moderate Redish Orange \\
\hline 11 & $\mathrm{~W} / \mathrm{K}+$ Goethite $(100: 21)$ & 49.35 & 30.36 & 23.02 & $8.0 \mathrm{R}$ & $4.8 / 7.6$ & 3.514 & Moderate Redish Orange \\
\hline 12 & $\mathrm{~W} / \mathrm{K}+$ Goethite $(100: 23)$ & 48.66 & 30.99 & 23.96 & $8.2 \mathrm{R}$ & $4.8 / 7.8$ & 3.982 & Moderate Redish Orange \\
\hline 13 & $\mathrm{~W} / \mathrm{K}+$ Goethite $(100: 25)$ & 48.12 & 31.49 & 23.99 & $8.1 \mathrm{R}$ & $4.7 / 7.8$ & 4.481 & Moderate Redish Orange \\
\hline
\end{tabular}

※ Grayish reddish orange color in which $\mathrm{L}^{*} \mathrm{a} * \mathrm{~b} *$ color space values are 52.50, 27.01, and 24.08, respectively.

$※ \Delta \mathrm{EH}$ : the color distance value between Shigaraki red clay and the experimental group.

경우는 Hematite로 전이 되면서 적색을 나타내지 못하 고 핑크색을 띄는 회색을 나타내었다. 이는 기존의 문헌 [6]과도 일치한다. 이를 Table 3과 Table 4에 나타내었다.

\subsubsection{White Kaolin에 Goethite 첨가한 UV 분석 결과}

개발하고자 하는 화장토의 조합은 하동 White Kalion $100 \%$ 에 Goethite를 $1,3,5,7,9,11,13,15,17,19$, $21,23,25 \%$ 씩 첨가하여 라꾸 시험편에 시유하여 건조 하였으며, 이것을 $800^{\circ} \mathrm{C}$ 에서 30 분간 유지 초벌소성한 후, 최고온도 $900^{\circ} \mathrm{C}$ 로 유지된 전기가마에 넣어 10 분간 소
성하여 색상을 분석하였다. 그 결과 하동 White Kalion에 Goethite가 증가됨에 따라서 명도 값은 감소하였고 색상 을 나타내는 $\mathrm{a} * \mathrm{~b} *$ 값은 증가 하여 밝은 색상을 나타냈다. 이를 Table 5와 Fig. 4에 나타내었다.

\subsubsection{White Kaolin에 Goethite(No.11)와 Wustite를 첨} 가한 $\mathrm{UV}$ 분석 결과

Table 5를 분석한 결과 하동 White Kalion $100 \%$ 에 Goethite $21 \%$ (11번)를 첨가한 시험편의 $\mathrm{a} * \mathrm{~b} *$ 값은 30.36, 23.02 로 일본 시가라끼 황토와의 거리 $(\mathrm{EH})$ 를 계산하여 

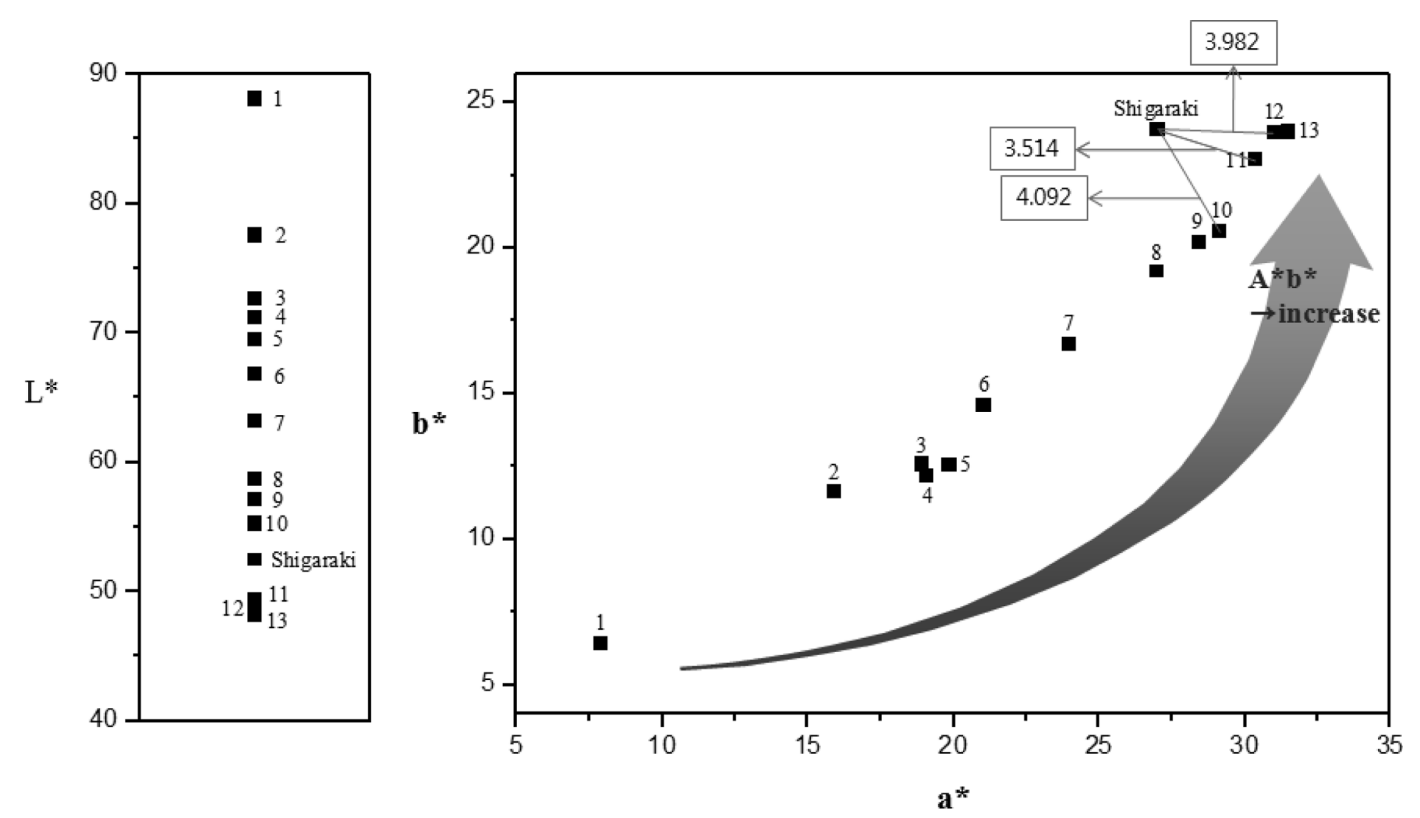

Fig. 4. Results of UV spectroscopic analysis after the addition of Goethite.

Table 6

UV spectroscopic analysis of the test piece after the addition of Goethite and Wustite

\begin{tabular}{llllllll}
\hline No. & Sample & $\mathrm{L}^{*}$ & $\mathrm{a}^{*}$ & $\mathrm{~b}^{*}$ & $(\mathrm{H})$ & $(\mathrm{V}) /(\mathrm{C})$ & Color name \\
\hline 21 & W/K + Goethite + Wustie $(100: 21: 1)$ & 49.59 & 29.98 & 22.02 & $7.8 \mathrm{R}$ & $4.9 / 7.4$ & Moderate Reddish Orange \\
22 & W/K + Goethite + Wustite $(100: 21: 3)$ & 49.09 & 30.45 & 22.02 & $7.7 \mathrm{R}$ & $4.8 / 7.5$ & Moderate Reddish Orange \\
23 & W/K + Goethite + Wustite $(100: 21: 5)$ & 48.69 & 31.02 & 23.24 & $8.0 \mathrm{R}$ & $4.8 / 7.7$ & Moderate Reddish Orange \\
\hline
\end{tabular}

※ Grayish reddish orange color in which $\mathrm{L}^{*} \mathrm{a} * \mathrm{~b} *$ color space values are $52.50,27.01$, and 24.08 , respectively.

비교한 결과 3.514 로 가장 비슷하였다. 시가라끼 황토와 같은 색상을 나타내기 위하여 하동 White Kaolin $100 \%$ 에 Goethite $21 \%$ 를 첨가 한 조합비에 각각 Wustite를 $1,3,5 \%$ 씩 첨가 하여 초벌한 시험편을 $900^{\circ} \mathrm{C}$ 에 넣어 10 분간 소성한 후 UV로 측정하였다.

그 결과 Goethite $21 \%$ 함유된 하동 White Kalion에 Wustite의 첨가량이 증가됨에 따라 명도 값은 감소하고 $\mathrm{a}^{*} \mathrm{~b}$ *값은 증가하여 시가라끼 황토와 비슷한 화장토를 개 발 할 수 없었다. UV색상 분석 결과를 Table 6과 Fig. 4에 나타내었다.

3.2.4. Raman 상대정량 분석법에 의한 $\mathrm{UV}$ 분석 결과 (White Kaolin에 Goethite와 Wustite를 첨가)

적색라꾸 화장토를 개발하기 위하여 시라가끼 황토를

Table 7

UV spectroscopic analysis of the test piece after the addition of Goethite and Wustite

\begin{tabular}{lllllllll}
\hline No. & Sample & $\mathrm{L}^{*}$ & $\mathrm{a}^{*}$ & $\mathrm{~b}^{*}$ & $\mathrm{(H})$ & $(\mathrm{V}) /(\mathrm{C})$ & EH & Color name \\
\hline 1 & W/K + Goethite + Wustite $(100: 5: 1)$ & 57.44 & 29.01 & 23.74 & $8.4 \mathrm{R}$ & $5.6 / 7.7$ & 2.029 & Moderate Reddish Orange \\
2 & W/K + Goethite + Wustite $(100: 5: 3)$ & 58.02 & 28.42 & 24.10 & $8.6 \mathrm{R}$ & $5.7 / 7.6$ & 1.41 & Moderate Reddish Orange \\
3 & W/K + Goethite + Wustite $(100: 5: 5)$ & 57.96 & 27.56 & 23.14 & $8.6 \mathrm{R}$ & $5.7 / 7.3$ & 1.089 & Moderate Reddish Orange \\
4 & W/K + Goethite + Wustite $(100: 5: 7)$ & 57.02 & 27.81 & 23.40 & $8.6 \mathrm{R}$ & $5.6 / 7.4$ & 1.05 & Moderate Reddish Orange \\
5 & W/K + Goethite + Wustite $(100: 5: 9)$ & 56.83 & 27.22 & 23.28 & $8.8 \mathrm{R}$ & $5.6 / 7.2$ & 0.827 & Moderate Reddish Orange \\
6 & W/K + Goethite + Wustite $(100: 7: 1)$ & 57.53 & 28.73 & 23.44 & $8.4 \mathrm{R}$ & $5.7 / 7.6$ & 1.835 & Moderate Reddish Orange \\
7 & W/K + Goethite + Wustite $(100: 7: 3)$ & 55.60 & 29.16 & 23.58 & $8.4 \mathrm{R}$ & $5.4 / 7.6$ & 2.207 & Moderate Reddish Orange \\
8 & W/K + Goethite + Wustite $(100: 7: 5)$ & 55.15 & 29.25 & 23.81 & $8.4 \mathrm{R}$ & $5.4 / 7.6$ & 2.256 & Moderate Reddish Orange \\
9 & W/K + Goethite + Wustite $(100: 7: 7)$ & 55.43 & 28.33 & 23.34 & $8.5 \mathrm{R}$ & $5.4 / 7.4$ & 1.513 & Moderate Reddish Orange \\
10 & W/K + Goethite + Wustite $(100: 7: 9)$ & 54.48 & 28.21 & 23.34 & $8.6 \mathrm{R}$ & $5.3 / 7.3$ & 1.41 & Moderate Reddish Orange \\
\hline
\end{tabular}

※ Grayish reddish orange color in which $\mathrm{L}^{*} \mathrm{a}^{*} \mathrm{~b} *$ color space values are 52.50, 27.01, and 24.08, respectively.

$※ \Delta \mathrm{EH}$ : the color distance value between Shigaraki red clay and the experimental group. 

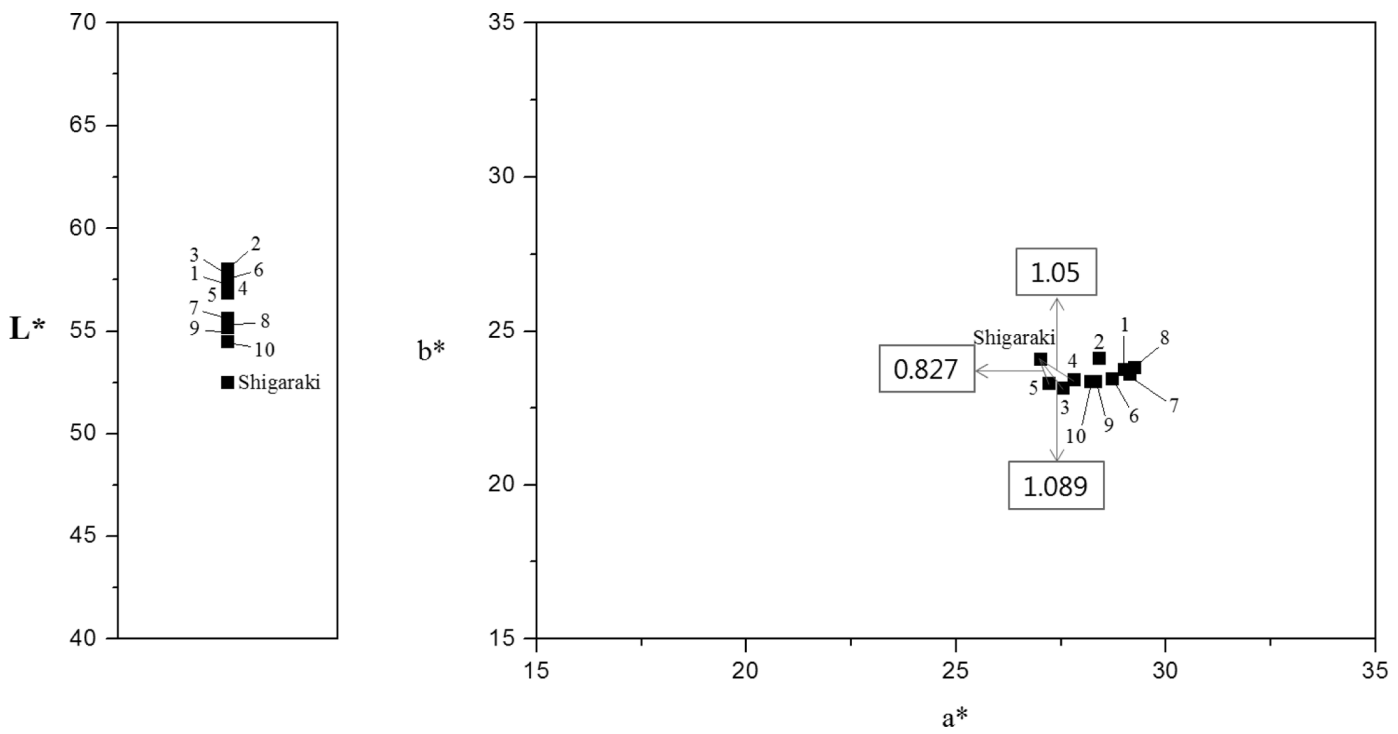

Fig. 5. UV spectroscopic analysis of the test piece after the addition of Goethite and Wustite.

Raman에 의한 “상대 정량분석법”[7-9]으로 분석한 결과 를 기초로 하동 White Kaolin $100 \%$ 에 Goethite를 5, $7 \%$ 및 각각에 Wustite를 $1,3,5,7,9 \%$ 씩 첨가하여 만든 화장토 시험편을 $900^{\circ} \mathrm{C}$ 에 넣어 10 분간 소성한 결 과 Table 7과 Fig. 5에 나타내었다.

그 결과 만들어진 화장토는 모두 Moderate Reddish Orange색을 나타내었으며 Goethite에 Wustite가 첨가됨 에 따라 색상을 나타내는 $\mathrm{a} * \mathrm{~b}^{*}$ 값은 감소되었다.

Fig. 5에서와 같이 일본 적색 화장토와 가장 비슷한 색상을 나타내는 것은 하동 White Kaolin $100 \%$ 에 Goethite $5 \%$, Wustite $9 \%$ 를 첨가하였을 경우이며, 측 정된 $\mathrm{a}^{*} \mathrm{~b}$ *값은 $27.01,24.08$ 로 시가라끼 황토와의 거리 $(\mathrm{EH})$ 를 계산하여 비교한 결과 0.827 로 가장 유사하였다.

본 연구 결과에서와 같이 하동 White Kaolin에 Goethite 와 Wustite의 첨가량을 조절함으로써 사용자가 원하는 색상의 적색 화장토를 제조할 수 있었다.

\section{4. 결 론}

1) 일본라꾸 도자기로 사용하는 시가라끼 황토 내에 함유된 산화철 $9.4 \%$ 에는 Goethite $5 \%$ 그리고 Wustite $4.4 \%$ 로 구성되어 있으며 $900^{\circ} \mathrm{C}$ 에 넣어 10 분간 소성 시 적색을 나타내는 것은 Goethite가 Hematite로 전이되면 서 Hematite에 Alumina와 Silica가 고용된 것으로 사료 되었다.

2) 하동 White Kaolin을 사용하여 적색라꾸 화장토를 개발할 경우 White Kaolin에 Goethite와 Wustite의 첨
가량을 변화시켜 다양한 적색을 내는 화장토를 만들 수 있다.

3) 현재 시가라끼 황토를 사용하여 만든 적색 화장토 와 같은 색상을 나타내는 조합은 하동 White Kaolin $100 \%$ 에 Goethite $5 \%$ 와 Wustite $9 \%$ 를 첨가한 조합이 었으며 UV색상은 $\mathrm{L} * 56.83 \mathrm{a} * 27.22 \mathrm{~b} * 23.28$ 이었다.

\section{참 고 문 헌}

[1] K. Raku, "What is raku?", $1^{\text {st }}$ ed. (Tankosha, 2002) p. 11.

[2 ] B.Y. Yang, T. Yokoyama and H. Takuchi, "New Technology: Learning Glaze", $1^{\text {st }}$ ed. (Sol Science, 2013) 461.

[ 3 ] T. Sasaki, "The Encyclopedia of Japanese History 29 Ceramic", 1 (1992) 182.

[ 4 ] H. Isono, "Rakudawan, 40" (Kaharasyoden, 1963).

[5] T. Yokoyama and H. Takuchi, "Report on the Development of Novel Rakuyaki Glaze Containing Iron", No.1 Development Assistance Group. Ceramic Team, Kyoto, Japan 1 (2011) 78.

[6] B.H. Lee and Y.J. Kwon, "The mechanism of red color formation of red clay for Japanese rakuyaki”, J. Ceram. Soc. 122 (2014) 5.

[ 7 ] R.L. McCreery, "Photometric Standards for Raman Spectroscopy", Ohio State University, USA (2002) 14.

[ 8 ] S.B. Hansen, "The Application of Raman Spectroscopy for Analysis of Multi-Component Systems" (Department of Chemistry 2000) p. 167.

[9] J.M. Chalmers and P.R. Griffiths, "Photometric Standards for Raman Spectroscopy" (John Wiley \& Sons Ltd, Chichester, 2002) p. 63. 